\title{
O TRIBUNAL DOS TRIBUNAIS: ONDE SE JULGAM AQUELES QUE JULGAM RACAS
}

\section{José Carlos dos Anjos \\ Universidade Federal do Rio Grande do Sul - Brasil}

Menos do que a questão das cotas parece estar em jogo, no artigo de Maio e Santos, o debate sobre a definição dos pesos relativos e das fronteiras dos lugares de enunciação do cientista e do político-militante quando o que está em jogo são identidades étnicas. Ou, pelo menos, é desse modo que o leitor é conduzido às "suas próprias” mais "razoáveis" reavaliações das questões envolvidas na problemática das cotas, sem que se sinta tomado pelo arrastão de uma posição política explícita e bem "fundada na razão".

A rodada de debates em torno da questão racial está sendo particularmente importante ao mundo acadêmico brasileiro por, de modo particularmente urgente, concreto e intenso, impor a discussão sobre a relação entre os lugares de enunciação do cientista e do político-militante.

E o artigo não deixa dúvidas quanto ao lugar privilegiado de onde está emergindo. Trata-se da ciência refletindo sobre seus próprios excessos, restaurando o tribunal de suas próprias práticas, discernindo as imposturas das trilhas seguras da razão. Nenhum outro lugar é tão razoável.

E que réu poderia ser tão apropriado quanto o incauto que, nos descaminhos dessa política infeliz, que é a política de raças, coloca em risco a purificação de uma ciência que já trilhou o purgatório? Sem dúvida, dentre as ciências, nenhuma constitui tribunal tão adequado para expurgação do racialismo quanto a antropologia, já que se ela ajudou a criar o monstro, é também o lugar de onde mais cedo e radicalmente se deitou o olhar mais distanciado sobre as pretensões de diferenças essenciais entre os humanos.

É buscando um assento no tribunal crítico do fazer com pretensões científicas que o artigo de Maio e Santos convida o julgamento-leitor à proscrição de práticas como a do antropólogo que aceitou fazer parte da comissão que iria analisar fotografias de 4 mil indivíduos para distinguir dentre eles brancos e negros. 
Desse lugar epistemológico de enunciação, carregado de pudores quanto a possibilidade de ser confundido com esse outro muito menos dotado de autenticidade, e naturalidade, que é o lugar da enunciação do políticomilitante, tudo o que os autores têm a nos dizer a respeito de cotas é apenas e suficiente. Apenas exterior à política para não conter nenhuma prescrição, nenhuma recomendação política, nenhuma alternativa.

Mas, também, é suficientemente proibitiva para tornar possível uma inscrição dissimulada na assembléia dos que têm coisas políticas a dizer sobre a problemática das cotas capaz de modelar esse espaço (limitando as possibilidades) de experimentação.

Acima e ausente da assembléia dos políticos-militantes, mas podendo acusar e chamar a política-pequena à razão, ${ }^{1}$ a velha posição do intelectual crítico - o "Eu acuso" de Zola - se instala à vontade no interior da questão racial, para desmontá-la.

A chamada do exterior, do lugar da ciência, a que a política se reajuste nos trilhos da razoabilidade científica, vem na forma de um alerta: "Correse o perigo de se enveredar pela construção de categorias essencializadas, fixas, próprias ao poder normativo das leis, aos desígnios das políticas públicas.”

O terreno é movediço quando simultaneamente se reconhece a existência de "injustiças raciais" e se pretende expurgar qualquer operacionalização da categoria raça. Radicalizando a posição de Fry (2004), se poderia dizer que qualquer reconhecimento de injustiças raciais termina numa experimentação com fotografias, isto é, em dispositivos que para desracializar começam realçando o fato da racialização.

${ }^{1}$ O risco de morte (Latour, 2004), que corre a política submetida às correções da razão científica, fica por demais evidente no modo da relação entre a militância política negra e as ciências sociais no Brasil, transferindo Latour, sob essa razão científica, "todo o esforço para racionalizar a fala política - impor-lhe o leito de Procusta da transferência de informação sem deformação - termina por tornar impossível o único procedimento, o círculo, cujo objetivo é dar existência provisória aos grupos. Se suspendêssemos a repetição contínua do círculo, simplesmente não existiriam (re)agrupamentos possíveis. Encontrar-nosíamos com agentes de limites fixos, que seriam proprietários exclusivos de suas falas: eles teriam interesses, vontades, identidades, opiniões. Eles nem seriam mais enunciáveis, nem denunciáveis; seus membros não poderiam mais se fazer representar, nem comandar, nem obedecer, nem mesmo pertencer" (Latour, 2004, p. 40). "Se minha hipótese é exata" continua Latour (2004) - "podemos perfeitamente imaginar uma época em que a fala política desapareceria ou, ao menos, tornar-se-ia de tal modo estranha que, quando pronunciada, seria sempre marcada pela proibição". 
Dispositivos como esse instalado na UnB, que experimentam a intensificação do processo de coisificação das raças (como inoculação para uma efetiva desracialização), causam o horror dos que apenas desconstroem e preservam da contaminação política "o máximo possível, a reflexão e a prática antropológica” (Oliveira, citado por Maio e Santos).

É claro que um antropólogo que assume o exercício prático em um dispositivo de correção de "injustiças raciais históricas” está inserido num lugar político de enunciação. E sua fala está dotada de uma inautenticidade congênita. Ele fala em nome de injustiçados que não lhe delegaram palavra e autoridade e que, felizmente, têm críticas a fazer sobre qualquer dispositivo que lhe seja montado para corrigir desigualdades raciais que "historicamente" eles mesmos ou seus ancestrais sofreram.

Todavia, se impõe reconhecer que ninguém nessa assembléia de discussões sobre a correção de injustiças raciais está em posição menos desconfortável. É característico da fala política ter de produzir uma diferença radical entre aquele que fala e aquele em nome de quem se fala. No dizer de Latour (2004, p. 38),

nenhuma semelhança pode ser possível, nenhuma transparência, nenhuma imediatez, nenhuma mimesis, nenhuma sobreposição [...] quando eu falo, é uma multidão de outros que falam ao mesmo tempo - seu nome, como para os demônios, é uma legião. Não surpreende que não economizemos nenhum esforço para evitar falar politicamente de alguma coisa.

A economia dos riscos de "falar politicamente" acionada por Maio e Santos é típica do desprezo que as posições críticas nas ciências humanas têm pela "enunciação política (e elas, aliás, não se privam disso), vendo na retórica política quase sempre uma "mentira que oculta os verdadeiros mecanismos e relações de dominação” (Latour, 2004, p. 38).

Para dirimir as dificuldades do leitor e evitar que corra os riscos que assumo aqui de imputar posições, devo esclarecer que falo do lugar da política e não reconheço quanto a esse tópico - da desracialização do mundo - a possibilidade da política ter bons conselheiros que não sejam eles mesmos lugares políticos de enunciação, mesmo se ocupados por cientistas.

Assumo aqui a posição de Latour de que as ciências devem assegurar lugares na assembléia de porta-vozes "quaisquer que sejam as controvérsias sobre a fidelidade, a importância, a multiplicidade de seus representados" (Latour; Schwartz; Charvolin, 1998, p. 123). É a isso que Oliveira (citado por 
Maio e Santos) se nega quando acusa de "ingenuidade sociológica" a pretensão de falar "por algum grupo ou força social" - traço definidor por excelência da fala política e seu por demais reconhecido calcanhar de Aquiles.

Avaliar que o antropólogo que assumiu um lugar na comissão de seleção para cotas se inseriu em uma configuração política que essencializa grupos sociais na forma de raças é uma leitura distorcida e parcial do que está em jogo no dispositivo que foi montado na UnB. Falar de raças num cenário de correção de injustiças raciais e apontando para a desracialização a um certo prazo deveria ser entendido como diferente de fazer a apologia de raças num contexto de promoção da superioridade de uma delas. Mas é como se sistematicamente uma parte desse enunciado fosse ignorada e a crítica ficasse fixa num único termo - raça - cujos efeitos se supõem que sempre escapariam das intenções de justiça social dos homens que a carregam e seriam automaticamente sempre nazistas.

A rodada da desconstrução de essências e desmontagem das categorias que configurariam grupos sociais naturais já rendeu seus frutos, e se pode conceder aos integrantes do "tribunal de raças" que se instalou na UnB o benefício da suposição de que sabem que em termos biológicos raças não existem para a humanidade.

O que está em jogo é como se pode constituir dispositivos que sejam funcionais numa desracialização que não deve ser apenas retórica. Se a racialização no Brasil não teve apenas efeitos de representação, as práticas que podem desconstituí-la talvez também não possam ser eficazes se estiverem limitadas ao domínio de uma pedagogia (des)racial. A construção de dispositivos práticos para a correção de injustiças raciais é do âmbito da ação política e demanda do cientista posições políticas de defesa de seus próprios desenhos de correção de injustiças raciais, numa assembléia em que militantes de movimentos sociais e cientistas estão em posições simétricas.

Aguardo uma assembléia de debates sobre os caminhos para a desracialização do país em que, em meio a representações provisórias e reconhecidamente frágeis, cientistas seriam porta-vozes de multiplicidades diferentes de configurações e dispositivos (des)racializantes ao lado de político-militantes tão frágeis quanto, e tendo que provar o valor de sua representação a todo o instante.

Terminaria propondo que tendo se reconhecido que existem injustiças raciais no Brasil, que os cientistas usem a imaginação científica e política 
para apresentarem outras possibilidades de construção de dispositivos desracializantes $^{2}$ em lugar da crítica exercida no confortável de tribunal de todos os tribunais - lugar em que os cientistas críticos insistem em camuflar posições que precisariam passar pelo teste da política em lugar dos jogos sem riscos típicos do lazer escolástico.

\section{Referências}

FRY, Peter. A lógica das cotas raciais. O Globo, Rio de Janeiro, p. 7, 14 abr. 2004.

LATOUR, B. Se falássemos um pouco de política? Política \& Sociedade: Revista de Sociologia Política. Florianópolis: Cidade Futura, n. 4, p. 11-41, abr. 2004.

LATOUR, B.; SCHWARTZ, C.; CHARVOLIN, F. Crise dos meios ambientes: desafios às ciências humanas. In: ARAUJO, H. R. (Org.). Tecnologia e cultura, ensaios sobre o tempo presente. São Paulo: Estação liberdade, 1998. p. 91-125.

${ }^{2}$ Não me parece lógico que se possam corrigir desigualdades raciais sem se enfatizar o processo de racialização já ocorrido, numa espécie de vacina ou lente de aumento que levaria a aquilo que os marxistas chamavam de "consciência para si", nesse caso, da racialização. Talvez não existam atalhos ao processo de visualização da racialização já ocorrida, como condição para uma sociedade sem raças. 